\title{
TECHNOLOGICAL TOOLS FOR ENHANCING TEACHING AND LEARNING PROCESS
}

\author{
Shazia Kouser \\ Ishfaq Majid
}

\begin{abstract}
In recent years technology has changed dramatically. Due to the increasing need and accessibility of technology, it has expanded the toolbox and provides opportunities to the teachers for using technology. Computer devices are considered to be the more powerful tools which have come in various forms. The internet helps connect those devices and can connect students in the classrooms, through schools or around the world. Now a day, there is an availability of computers and interactive boards in schools, and the schools were connected as well as to the whole world providing high-speed network connectivity. Technology present in schools in the form of tablet devices, smartphones, and laptop computers are now used as a part and parcel of the teaching-learning process. The objective of the current study is to provide information about various technological tools that help enhance the teaching and learning process. These tools can help the teachers in creating, manipulating, using and sharing information over the networks.
\end{abstract}

Keywords: Technology, Technological tools, School Education, Higher Education.

\section{INTRODUCTION}

As we all are now living in a digital age and the learners of today's generation have different needs and requirements. The learning must not be limited to the classroom only; it must be confined outside the classroom also. Digital technology has the potential for making a substantial contribution to enriching education for all areas of Curriculum that strives for Excellence. If the technology is effectively used, it will result in enhancing the teaching and learning by digital technology (Edinburgh, 2016). In our day to day life, the advancement of technology is increasing all over the world and in everyone's life. Many jobs were not having any requirement of technology but now are in dire need of technology (Costley, 2014). Many individuals are using technology in their daily routine of life. The individual's day starts with their alarm on the phone and ends up with what's app messages. Many 
Youngsters feel happy and satisfied to make use of technology and due to this, we can integrate technology in education for making the teaching-learning process systemic and efficient so that the learners can learn in a good and happy mood.

Technology has originally come from the Greek word techno logia. The word techno logia became technology and it comes into existence. The word was used in the seventeenth century for the first time. Many people think that the word technology only means that the mobile, internet computer, laptop etc. They further believe that technology is nearby to them, the growth among them like new languages, the building of new websites and the new creativity in the field of computers that is only the technology. But if we talk about the proper meaning of technology, it means the scientific knowledge that can be used for solving many practical problems especially in the field of commerce and industry. Various types of materials and methods are being used for solving the practical problems that denote that the technology is not restricted to computer and internet only. It is much wider than that. The satellite and switchboards in our houses are also a part of technology. Technology Changes because the needs and requirements of human beings are unlimited.

For the successful completion of various activities and tasks in different sectors like the use of technology in the educational sector have been applied for improving and making the teachinglearning process more appropriate, effective and efficient for the students as well as for the teachers. Students in today's schools are lucky enough to have access to many technology equipment's and Internet technologies (Baytak et. al., 2011). While incorporating technology in teaching makes lessons fun and joyful for the students, the students can learn at their own pace that is at anywhere and at any time they can easily access the desired content with the help of technology and can learn easily. "How teachers learned subject matter is not necessarily the way their student will need to be taught in the 21 st century" (Niess, 2005, p. 509). Technological use in teaching and learning can bring improvement in the performance of students and can bring positive learning outcomes. While making use of technological equipment like Interactive Whiteboard, the interest among learners can be increased towards learning. The students can learn easily and then the classroom will become a happier place of learning for each student whether the child is slow learner, backward, or a disabled. Teachers can teach the students by applying various technological skills which also helps them for improving their teaching in a more advanced way i.e. according to the need and interest of the child the teacher designs his or her teaching pedagogy. 


\section{THE ROLE OF TECHNOLOGY IN EDUCATION}

In today's schools and classrooms learning with technology is of utmost importance. The worldwide educational systems, researchers, parents, governments, leaders, and teachers considered the technology to be a dire need of the child's education. In Australia it was recognized that the technological advances influence the people's way of sharing, creating, using and developing information in the society. The young people must be highly skilled in using information and communication technologies (ICT). The teachers who are teaching since many years can integrate with the recently graduated teachers. The reason behind this is that recently graduated teacher are well aware of the technology and can benefit their colleagues. These two groups of teachers can work together for planning lessons that use the strengths of the teaching and learning process of both (Ranasinghe \& Leisher, 2009).

There is a need to prepare students for the society and also to keep pace with society are the main reasons behind using technology in education. Researchers and educators have pointed to the technology for increasing motivation and engagement among the learners. Catering for the various styles of learning and for improving the learning outcomes.

For making the teaching-learning process more effective the teacher uses various technological tools for the learners and the technological tools help enrich the effective teaching-learning process. Teachers in the teaching-learning process can use these modern technologies to build their assessment, to convey the tasks to those students for which it is made (Majid, 2019).

\section{Easy class}

Easy class is a free and simple online learning management system. It is made especially for the educators and the students. Here, the teachers can create online courses for the students and they can access at any time, and at any pace. Teacher can make important announcements and share materials and files in a well-organized and systematic manner. It includes assignments, class discussions, quizzes, and even exams and results. The grade points of the students are also being updated including the feedback to the students that is provided at the end of the exam and then it is displayed to the students by utilizing this platform. This tool provides opportunities to the teachers for engaging the students in different activities through which a dimension for interaction and the learning increases and becomes efficient. The main aim of this online platform is to democratize and to promote global education among the learner community by providing them with free access to the platform. 


\section{Microsoft Teams}

It is a hub for teamwork in office 365 which brings everything together where people can work in teams by cooperating and collaborating. It includes various options like chatting knowing the opinions and each other's personality along with that the use of emoji's, gifs and stickers. A team of peoples like 10 or 10,000 group of peoples can meet in one place and it does not matter from where they belong. There is also a calling option in Microsoft teams where the calling is done in teams and even they all can collaborate in one place no matters whether they are from different regions or any part of the country. In teams, they can share, access and even edit word documents, PowerPoint and Excel files in real-time. This type of technology has united many minds together and due to which they have achieved their aims and objectives to be accomplished. Microsoft Teams is a place where online documents, announcements, favourite websites, discussions, grade books, and the videos can be found by the students easily (Williams, 2020).

\section{Zoom Classrooms}

It is also one of the tools for learning management system. The web-based video conferencing and digital classroom system allow communicating face to face, two-way video $\&$ audio where up to 100 people can join. They can be in small groups or large groups. For using the zoom platform as a teacher, instructor or an educator we need a device with the microphone and a camera. It increases student's participation and learning retention with the combination of virtual and hybrid classrooms and also the micro-learning. Zoom has many innovative features that help a teacher in delivering online lessons. It can be delivered by engaging students with a chat feature, using videos, sharing and recording lessons. For using the zoom tool you need to download the zoom software by using the link www.zoom.us. It can also be downloaded from the mobile phone and the main device must be desktop or laptop. All you need is to make a schedule of meeting or lesson for getting a link (Personal Meeting ID) which can be shared by the educator with the students and the students can use that link for their identification. The feature of zoom helps teachers for exploring and accessing the skills while interacting with students. It makes lessons more interactive and the students can also record the lessons and they can use the recording at any time for learning. Participants can join this online platform by using the basic (free) package and then if they need more they can buy by using paid monthly packages/add -on packages.

\section{Near pod}


Near pod is also one tool that is made for the student's Engagement. It is a Platform where the interactive lessons were being practised by the teachers. Near pod offers teachers an easy-to-use tool for creating interactive lesson plans, presentations, assessments, and digital content. Near pod allows teachers to create digital lesson plans, share it with students during class, and track individual progress. Lessons are comprised of teacher-created slides that can include text, video, images, websites, questions, quizzes, polls, and assignments. Students can follow the lesson on their own devices at their own pace or teachers can lead a synchronized session where students can follow the lesson in realtime.

\section{Mentimeter}

Mentimeter is an interactive learning platform where you can make your audience that they feel involved by enabling them for contributing to the presentations with smartphones and showing the live results. A Swedish company that finds innovative ways to create presentations with real-time feedback. The web and app interface enables users to share knowledge and real-time feedback on mobile. Mentimeter has a lot of other options like presentations, polls or brainstorming sessions in classes, meetings, gatherings, conferences and other group activities. A teacher after uploading the desired PowerPoint Presentation creates a unique six-digit code. The students who want to access that content are directed to enter the unique code to start viewing the PowerPoint on the web. The Swedish based company was ranked as Stockholm's fastest-growing company of the 2018 edition of the Dagens Industri Gasell Award. Make your audience feel involved by enabling them to contribute to presentations with their smartphones and show them the live results.

\section{Google Form}

Google form is used in the area of business and educational purposes. It is a free online teaching and learning platform which everyone can easily use. It is used mostly by the educators which allow them to create forms, quizzes, result declaration grading, item analysis, surveys and collaborative editing. The form can be shared with other people. Google forms are also used for assessing the students and for checking the child's previous knowledge. These forms can be applied for giving and receiving feedback from the students and parents also. Similarly, the students can make use of Google forms for accessing their learning and they can fix the learning goals for collecting data for research projects. While using Google forms it provides templates for users like feedback and course evaluation. For designing our own Google form we can select the blank template. Many types of questions can be asked in Google form which includes short answer, multiple-choice, responses through paragraph, 
checkboxes, linear scales etc. we can also include images and videos directly in the form which helps in accessing the students thinking and learning after they have viewed the image or video. The data collected from Google forms are collected by using Google spreadsheet, which provides further analysis.

\section{Google Classrooms}

Google Classroom is an online teaching-learning platform and a free web service that has been developed by Google for schools. Here the teachers can create online classrooms where they can upload the teaching material and can conduct online quizzes. The main purpose of Google Classrooms is to update and share the files between teachers and learners. It is a combination of Google Drive, Google docs, slides and sheets for writing. Gmail is used for communication and the Google calendar for scheduling. The students are invited for joining a Google classroom through a code and later on the calendar was integrated.

\section{Google Hangouts Meet}

Google Hangouts Meet is a video communication service that was developed by Google. It is a combination of two apps. One is the new version of Google Hangouts, and another is the Google hangouts chat. The new meet experience provides the outline for connecting with people on campus or outside the campus. You can have 5 peoples joining your conference at a time Through the use of Video Conferencing the students and teachers are connected for the purpose of teaching and learning.

\section{YouTube Videos}

Youtube was started as a video distribution platform in the year 2005 and now it has become most popular and most visited site across the world. It is an important tool of teaching and used mostly by educators for the purpose of teaching. It can also be used for some other purposes like advertising for running their business in many different fields. Educators can make their classroom channel and all the lectures were uploaded in videos in the form of content, audios and videos. After the site have been launched some educational institutions like open courseware and TED have started using it for distributing their content through online mode in the form of videos.

Apart from all these, we can also make use of synchronous mode where the teacher and learners both are present at the same time and asynchronous mode is also there where Teaching-learning material is posted online and the learners can learn whenever they get the time and according to their wish they 
can learn. Educators can record their course video lectures and then they can upload them on any learning management system. Some instructors can use various social media sites for their content display like they can make groups on Facebook, WhatsApp and many others also.

\section{CONCLUSION}

The technology pace in society and in schools has been exponential and will continue to be so. Teachers are using technology for supporting their role in equipping the students with structure and advice, checking progress and evaluating their activities. Students are using technology for conducting research projects, analyzing data, solving problems, designing products and assessing their work. Students can work with others for creating and communicating new knowledge and understandings. The strategies based on the theories of learning that allow the teachers to provide different learning experiences for their students. With time the technology is changing all the time and what we know about how to use that technology effectively. The teacher must develop practice and understanding regarding technological use to help the students learn effectively. 


\section{References}

Baytak, A., Tarman, B., \& Ayas, C. Experiencing technology integration in education: children's perceptions. International Electronic Journal of Elementary Education, 3(2011), 139-151. Retrieved from https://files.eric.ed.gov/fulltext/EJ1052441.pdf

Costley, K. C. The Positive Effects of Technology on Teaching and Student Learning. (2014). Retrieved from https://files.eric.ed.gov/fulltext/ED554557.pdf

Edinburgh. Enhancing Learning and Teaching Through The Use Of Digital Technology. (2016) Retrieved from https://planipolis.iiep.unesco.org/sites/planipolis/files/ressources/scotland_dig_tech_00505855.pdf

Majid, I.. ICT in Assessment: A Backbone for Teaching and Learning Process. United International Journal for Research \& Technology, 1(2019), 38-40. Retrieved from https://uijrt.com/v1i3/uijrtv1i30006

Niess, M. Preparing teachers to teach science and mathematics with technology: Developing a technology pedagogical content knowledge. Teaching and Teacher Education, 2(2005), 509-523. Retrieved from https://doi.org/10.1016/j.tate.2005.03.006

Ranasinghe, A. L., Leisher, D. The Benefit of Integrating Technology into the Classroom. International Mathematical Forum, 4(2009), 1955 - 1961. Retrieved from http://m-hikari.com/imfpassword2009/37-40-2009/ranasingheIMF37-40-2009.pdf

Williams, D.. How Microsoft Teams Can Enhance a Learning Environment. GoGuardian. (2020). Retrieved from https://www.goguardian.com/blog/technology/how-microsoft-teams-can-enhance-alearning-environment/

Shazia Kouser

Research Scholar, School of Education

Central University of Gujarat

\&

Ishfaq Majid

Research Scholar, School of Education

Central University of Gujarat 